\title{
Finding Joe: Patient-directed goal setting on the journey to therapeutic targets in diabetes
} Health Design

\section{EDITORIAL}

\section{care}

\author{
Catherine Krejany, Moyez Jiwa
}

Melbourne Clinical School, The University of Notre Dame Australia, Werribee, VIC, Australia

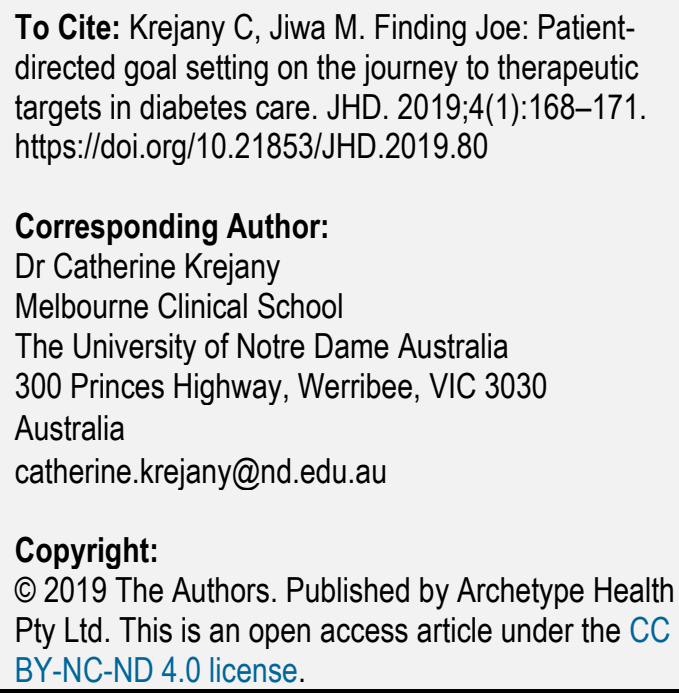

To Cite: Krejany C, Jiwa M. Finding Joe: Patientdirected goal setting on the journey to therapeutic targets in diabetes care. JHD. 2019;4(1):168-171. https://doi.org/10.21853/JHD.2019.80

\section{Corresponding Author:}

Dr Catherine Krejany

Melbourne Clinical School

The University of Notre Dame Australia

300 Princes Highway, Werribee, VIC 3030

Australia

catherine.krejany@nd.edu.au

\section{Copyright:}

(C) 2019 The Authors. Published by Archetype Health

Pty Ltd. This is an open access article under the CC

BY-NC-ND 4.0 license.

\section{SUMMARY}

Involving patients as active and engaged participants in their own health care is imperative for effective diabetes management. Shared decision-making is the leading model for this process yet medication adherence remains at sub-optimal levels. Currently, much of the decision-making conversation is still physician-directed and centres on therapeutic target setting, which is unrealistic and unachievable for many patients. Perhaps it is time to rethink a one-size-fits-all target destination and instead focus on a pathway built by patient-led sustainable and achievable goals.

\section{Key Words}

Diabetes care; medication adherence; shared decision-making; patient experience

\section{INTRODUCTION}

I'd like you to meet Joe.

Joe is 35 years old and a father to two young children. He works in an office in a small cubicle. His work is busy but mundane. He has a few good friends in the office but most of the day he is bored and uninspired. He has noticed that he is getting a little chubby lately. To relieve the boredom at work he meets up with colleagues for a mid-morning muffin and coffee. And a mid-afternoon snack. In the evenings he is busy with the kids but sometimes carves out some time for himself in front of the TV when he enjoys a small snack and a glass of wine. He occasionally meets up with friends for a couple of beers on weekends at the local football game. Joe's BMI is about 26 but he is putting on nearly $2 \mathrm{~kg}$ per year with his snacking habits that have a calorie value of a fifth meal. By the time Joe is 45 he has a BMI of 30 and when he visits his GP he is found to be diabetic.

How do we help Joe?

When he visits his GP, Joe will be informed about his diabetes. He will be told about something called HbA1c and will learn what glycaemic control means. He will be shown how to measure and monitor his blood sugar and be told what the consequences are if he doesn't. Then, possibly via a diabetes educator or nutritionist, Joe will be sent on his way. He will have been given the following advice: reduce your calories, learn what you can and can't eat, take some exercise, visit your dietician, take your daily medication, and come back for review in three months.

This is what the guidelines recommend for diabetes management. The guidelines and therapeutic targets have been developed for maintenance of glycaemic control and are necessary to prevent the serious sequelae of chronic illness associated with diabetes. ${ }^{1}$ This is undisputed. Well-controlled diabetes will decrease the odds of retinopathy, neuropathy, hypertension, hyperlipidaemia, kidney disease, and some neoplasms. Nobody is disagreeing with this. Not even Joe. 
But let's look at this situation from Joe's perspective. Within the space of a couple of weeks he's been told that he has diabetes and his health is at serious risk. All he has to do to make it better is to change his lifestyle. Easy right? "My muffin and coffee; the one thing that gets me through the drudgery of my morning... I guess that's got to go. And that banana in the afternoon, best not have that either. Those potatoes I really like with my roast dinner... pass. Those beers I look forward to on the weekends with friends... that's a no. And that medication they gave me might give me the runs really bad, but I guess I'll just have to live with that. After all I did this to myself, didn't I?"

Joe comes back to visit his GP in three months and is devastated to hear his HbA1c is at 9. Joe tells his GP that he has changed his diet drastically, cut out his snacking, takes regular walks and lost a little bit of weight. He also admits he has skipped on his medication occasionally because he couldn't risk the side effects: like that time he went on a driving holiday with his family, or his brother's wedding weekend, and maybe a couple of other times as well. Our friend Joe is now what, in the medical field, we would call "non-compliant". These terms are pervasive in the medical literature: non-compliance, non-adherence, non-concordance with treatment. In the context of diabetes, the rates are very high. ${ }^{2,3}$ It is clear that patients are simply not doing what their doctors are telling them.

Any medical professional who works in the field of diabetes understands that there is nothing simple about diabetes management. There is a plethora of studies aiming to improve care for patients with diabetes, including the development of a shared-decision making model aimed to improve patients' self-efficacy and self-management skill sets by involving patients more in decision-making. ${ }^{4}$ However, in moving towards a shared-decision making model, much of this approach is still driven by therapeutic target setting with limited evidence of effect. ${ }^{5,6}$

Nobody is suggesting throwing out the therapeutic guidelines and professional associations concur that patient-centred care is imperative. ${ }^{1,7}$ However, therapeutic targets cannot be the only driver of the consultation. If we look at what patients are saying about how these therapeutic targets are affecting their quality of life, we may find the answers, on an individual level, for why so many patients are considered "non-compliant". A large body of literature has evaluated the patient perspective on diabetes care and many themes have been identified. A couple of choice quotes illustrate a sample of issues around ability and perceived control, the lived experience, and compliance:

"You walk in my shoes... live pay check to pay check like we do, and not on your doctor's salary, and see what I have to work with. Then tell me that I need to do better. I do the best I can. This is what I have. If you could help me with what I have, then I'll listen to what you have to say. I know my A1C is not where it should be. I don't need to you to drill that into me every time I come."

"Honestly, you are then handed from one seminar on nutrition to the next: they always tell the same stories, I am not to drink beer anymore, I am not to eat any pork knuckle, oh, my Sunday roast is forbidden, and, and, and, oh, everything is forbidden, this is so on principle, that is just the other end of the scale, I am not allowed anything, I'm just going home, they can kiss my ass, they achieve just the opposite of what is aimed for."

"I ate a brownie, but my blood sugar didn't go up," "I turned down my mother's tamales, and hurt her feelings, but my glucose didn't go down."10

"I'll take it for a while, and then go, nah, this is too difficult. You've turned it into a burden and a chore, and it's my health... there are things I've got to do that non-diabetics don't have to, but they don't have to be to the extent where your life becomes completely secondary to it." 11 
Often suggestions to improve compliance rates focus on educational interventions for patients, or doctors, or both. Programs to improve patients' health literacy, interventions to increase review and screening attendance rates, changes to doctors' information delivery, cultural competency, setting, and social context, have all been suggested., ${ }^{3,12,13}$ Effectively, doctors need to say it better and patients need to be taught how to hear the message. While these interventions and approaches are valuable changes, this is not the whole story. A significant part of the puzzle is often overlooked in the design of such innovations. In the myriad techniques and healthcare redesign we have lost Joe's voice.

In our consultations we involve patients in decision-making about targets and goals we have already set in line with current guidelines. These may be unachievable or unacceptable for many patients in their current circumstances. Working in a truly collaborative sense may have more chance to help patients move towards therapeutic targets in a way they can manage, rather than introduce the very high risk of failure to comply with treatment. When presenting our recommendations we need to carefully consider whether our suggestions are in conflict with patient priorities and preferences. Viewing patients' progress though a narrow lens of compliance is unhelpful and overly simplistic. We need to understand their point of view and negotiate the small changes that build patients' capacity and readiness to make sustained behaviour changes. Many of our recommendations challenge patients' world view, autonomy, and sense of self. We need to respectfully acknowledge and recognise these challenges, understand the patients' lived experience, and how that impacts on what messages they are ready to receive. When designing healthcare solutions for all patients, we need to look for, and find, Joe.

\section{REFERENCES}

1. Royal Australian College of General Practitioners. General practice management of type 2 diabetes: 2016-18. East Melbourne, Victoria, Australia: The Royal Australian College of General Practitioners; 2016. [Accessed 2019 JAN 8]. Available from: https://www.racgp.org.au/clinical-resources/clinical-guidelines/guidelines-by-topic/chronicdisease/management-of-type-2-diabetes

2. McGovern A, Tippu Z, Hinton W, et al. Comparison of medication adherence and persistence in type 2 diabetes: A systematic review and meta-analysis. Diabetes Obes Metab. 2018;20(4):1040-3. https://doi.org/10.1111/dom.13160

3. Polonsky WH, Henry RR. Poor medication adherence in type 2 diabetes: recognizing the scope of the problem and its key contributors. Patient Prefer Adherence. 2016;10:1299-307. doi: 10.2147/PPA.S106821

4. Légaré F, Adekpedjou R, Stacey D, et al. Interventions for increasing the use of shared decision making by healthcare professionals. Cochrane Database of Systematic Reviews 2018(7). https://doi.org/10.1002/14651858.CD006732

5. Shay LA, Lafata JE. Where is the evidence? A systematic review of shared decision making and patient outcomes. Med Decis Making. 2015;35(1):114-31. https://doi.org/10.1177/0272989X14551638

6. Saheb Kashaf M, McGill ET, Berger ZD. Shared decision-making and outcomes in type 2 diabetes: A systematic review and meta-analysis. Patient Educ Couns. 2017;100(12):2159-71. https://doi.org/ 10.1016/j.pec.2017.06.030

7. Inzucchi SE, Bergenstal RM, Buse JB, et al. Management of Hyperglycemia in Type 2 Diabetes: A Patient-Centered Approach. Diabetes Care. 2012;35(6):1364. https://doi.org/ 10.2337/dc12-0413

8. Stiffler D, Cullen D, Luna G. Diabetes Barriers and Self-Care Management: The Patient Perspective. Clin Nurs Res. 2014;23(6):601-26. https://doi.org/10.1177/1054773813507948

9. Buchmann M, Wermeling M, Lucius-Hoene G, et al. Experiences of food abstinence in patients with type 2 diabetes: a qualitative study. BMJ Open. 2016;6(1):e008907-e07. https://doi.org/10.1136/bmjopen-2015-008907

10. Hunt LM, Arar NH, Larme AC, Rankin SH, Anderson RM. Contrasting patient and practitioner perspectives in type 2 diabetes management. West J Nurs Res. 1998;20(6):656-82. https://doi.org/10.1177/019394599802000602

11. Burridge LH, Foster MM, Donald M, et al. Making sense of change: patients' views of diabetes and GP-led integrated diabetes care. Health Expectations: An International Journal Of Public Participation In Health Care And Health Policy. 2016;19(1):74-86. https://doi.org/10.1111/hex.12331 


\section{The
Journal of
Health Design}

12. Duke SAS, Colagiuri S, Colagiuri R. Individual patient education for people with type 2 diabetes mellitus. Cochrane Database of Systematic Reviews. 2009(1). https://doi.org/ 10.1002/14651858.CD005268.pub2

13. Capoccia K, Odegard PS, Letassy N. Medication adherence with diabetes medication: a systematic review of the literature. Diabetes Educ. 2016;42(1):34-71. https://doi.org/10.1177/0145721715619038

\section{ACKNOWLEDGEMENTS}

None

\section{PEER REVIEW}

Not commissioned. Externally peer reviewed.

\section{CONFLICTS OF INTEREST}

The authors declare that they have no competing interests.

\section{FUNDING}

None

\section{ETHICS COMMITTEE APPROVAL}

None 